\title{
Impact of Pulmonary Tuberculosis Activity on Exhaled Breath Markers Levels in the Egyptian Population
}

\author{
Ahmed Mohammed Abumossalam ${ }^{1,2^{*}}$ (D), Ahmed Ehab ${ }^{1,3}$, Hanan Abdelsattar Elhalaby ${ }^{4}$, \\ Mohamad Darwish Mohamad5, Tamer Ali Elhadidy ${ }^{1}$ \\ ${ }^{1}$ Department of Chest Medicine, Faculty of Medicine, Mansoura University, Mansoura, Egypt \\ ${ }^{2}$ Respiratory Medicine, Respiratory Therapy Department, Faculty of Medical Rehabilitation Sciences, Taibah University, \\ Al-Medina Al-Munwarah, Kingdom of Saudi Arabia \\ ${ }^{3}$ Respiratory Medicine, Loewenstein Lung Center, Loewenstein, Germany \\ ${ }^{4}$ Department of Pediatric Medicine, Faculty of Medicine, Mansoura University, Mansoura, Egypt \\ ${ }^{5}$ Department of Clinical Pathology Medicine, Faculty of Medicine, Mansoura University, Mansoura, Egypt \\ Email: ‘abumossalam79@yahoo.com, Hanan_elhalaby@yahoo.com, Mohamad_darwish_79@yahoo.com, \\ hadidy1980@yahoo.com
}

How to cite this paper: Abumossalam, A.M., Ehab, A., Elhalaby, H.A., Mohamad, M.D. and Elhadidy, T.A. (2020) Impact of Pulmonary Tuberculosis Activity on Exhaled Breath Markers Levels in the Egyptian Population. Journal of Tuberculosis Research, 8, 22-32.

https://doi.org/10.4236/jtr.2020.81003

Received: February 10, 2020

Accepted: March 24, 2020

Published: March 27, 2020

Copyright $\odot 2020$ by author(s) and Scientific Research Publishing Inc. This work is licensed under the Creative Commons Attribution International License (CC BY 4.0).

http://creativecommons.org/licenses/by/4.0/

\begin{abstract}
Introduction: Tuberculosis still characterizes till now a major respiratory insult with concurrent pulmonary manifestations and later disability. Aim of Work: To evaluate the level of exhaled fraction of nitric oxide (FENO) and fraction of exhaled carbon monoxide (FECO) as markers of pulmonary tuberculosis $\mathrm{TB}$ activity in patients under chemotherapy in comparison to healthy negative patients and latent TB patients. Patients and Methods: This cross-sectional study was conducted on 130 patients recruited from the outpatient clinic of Mansoura Chest hospital during the period from May 2019 to December 2019. They were categorized into the three groups: 1) Pulmonary tuberculous patients PTB (group1) which included 48 cases with positive sputum for TB bacilli in the initiation phase after 1 month of starting anti-tuberculous chemotherapy; 2) Latent patients (group 2): included 40 patients with positive tuberculin skin test (Mantoux test) $>10 \mathrm{~mm} .3$ ) Control patients (group 3) which included 42 healthy volunteers with negative sputum for TB bacilli. They were subjected to portable spirogram as well as exhaled fractional NO and CO measurement. Results: FECO and FENO levels prevailed in pulmonary TB patients followed by Latent TB patients and lastly healthy volunteers $(42 \pm 12.32 / 5 \pm 0.16 \& 38 \pm 8.25 / 6 \pm 2.25$ and $23 \pm 3.25 / 2 \pm 0.40$ respectively). Conclusion: Measurement of $\mathrm{CO}$ and NO level in expired air may correlate with active pulmonary TB infection in comparison to healthy negative tuberculous patients and latent tuberculous patients.
\end{abstract}




\title{
Keywords
}

\author{
Latent TB, Exhaled CO, FENO, ESR
}

\section{Introduction}

Eminent diagnosis of pulmonary TB, primarily at the critical care level, counted on obtaining an adequate sample of the bronchial airway as enough expectorated sputum. The basic typical tool for diagnosis of active pulmonary TB relied on the bacteriological culture, alongside with nucleic acid amplification test (NAAT) plus microscopic examination of obtained smear however in one-third of TB patients no adequate biological sputum sample could be acquired [1]

This dictated more different sampling methodologies for fear of failure of diagnosis altogether that was recognized in many low resource communities. Thus, alternate non-invasive techniques, such as blood, urine samples [2] and exhaled breath condensate [3] supported aides in TB diagnosis.

Numerous research teams had utilized gas chromatography (GC) interrelated to mass spectrometry (MS), for inspecting the volatile molecules detected in breath in cases with active pulmonary TB, and detected diverse forms of marker compounds [4] [5] [6] owing to different sampling methods and analytical approaches along with patient population heterogeneity and patient comorbidities [7].

Overall, breath chemical composition could be affected by varied respiratory infections, food, drug medications, and smoking habits in addition to age and gender [8], but less prominent as smoking behaviors do [9]. Also, the profile of compounds possibly created during MTB infection may be altered by the host at different phases of infection and could be variable during the progression/regression of TB disease [5].

Currently, most researchers had focused on exhaled nitric oxide (NO), although recently quite a lot of other volatile gases (carbon monoxide, pentane, ethane) had also been investigated. Moreover, multiple endogenous substances (inflammatory mediators, cytokines, oxidants) were identified in expired breath condensates. In patients with active tuberculosis elevated exhaled NO and NOS2 presentation in alveolar macrophages was established and seemed to vanish with antituberculosis therapy [10].

On the other hand, elevated exhaled CO levels offered an initial warning indicator for an acute pulmonary infection, which was associated with exacerbation of an existing respiratory disease, moreover lower respiratory tract infections other than pulmonary TB [11], thus our study aimed to evaluate the level of exhaled fraction of nitric oxide (NO) and carbon monoxide $\mathrm{CO}$ as markers of pulmonary $\mathrm{TB}$ activity in patients under chemotherapy in comparison to healthy negative patients and latent $\mathrm{TB}$ patients. 


\section{Patients and Methods}

This an observational cross-sectional concurrent parallel study.

\section{Patients.}

This study was conducted on 130 patients who were recruited from the Outpatient Clinic of Mansoura Chest Hospital. The practical part of this study was carried out from May 2019 to August 2019 while the theoretical and statistical part was conducted during the period from August 2019 to December 2019. The selected patients were at age (13 - 55 years) who were referred for medical advice for TB treatment at Mansoura Chest Hospital Outpatient Clinic, National TB program. Control patients were selected from patients' relatives with a negative history of pulmonary diseases and a negative (tuberculine Monteux test and sputum smear) and nonsmokers with the same age group.

They were categorized into three groups:

1) Pulmonary tuberculous patients (group 1): which included 48 (sputum positive smear pulmonary tuberculous) (PTB) patients after 1 month of starting antituberculous chemotherapy during the initiation phase.

2) Latent patients (group 2): included 40 patients with positive tuberculin skin test (Mantoux test $0.1 \mathrm{ml} \mathrm{PPD}$ purified protein derivative containing $5 \mathrm{TU}$ ) $>10$ $\mathrm{mm}$ with negative history of TB infection in endemic area (Egypt) and high risk groups (pulmonary TB contacts).

3) Control patients (group 3): which included 42 healthy volunteers with a negative history of pulmonary diseases and negative (tuberculine Monteux test and sputum smear) and nonsmokers with the same age group.

Exclusion criteria: Included:

1) Current Smokers;

2) Asthma;

3) COPD;

4) Inhalational lung injury;

5) Interstitial lung disease;

6) Chronic debilitating diseases, autoimmune disorders and hematological disorders.

The procedure:

All patients were subjected to the following:

1) Clinical assessment (full history taking and clinical examination);

2) Laboratory investigations:

a) Routine laboratory investigations:

- Complete blood count, Liver function and Kidney function tests;

b) Erythrocyte sedimentation rate and $\mathrm{C}$ reactive protein;

c) Sputum eosinophil level.

3) Pulmonary function test:

Portable Spirogram: measuring FEV1, FVC, FEV1/FVC ratio PEFR was conducted with three alternative sensors for the Discovery device for the three groups with infection control policy, Figure 1 Infection control policies were carried out 


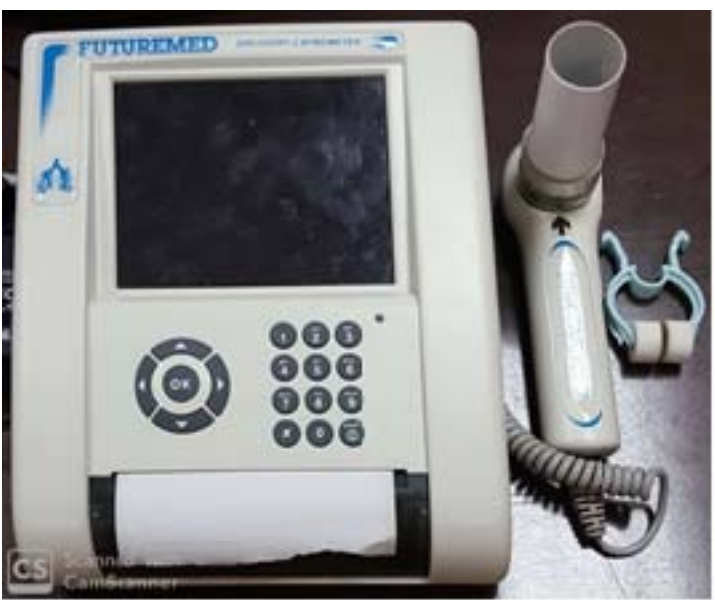

Figure 1. Discovery Device 2, portable Spirogram, Future Med. (America. Inc., 15700 Devonshire St., Granada Hills, CA 91344-7225, USA).

ensuring personal hygiene using disposable mouthpieces, nose clips and barrier filters. Sensors were sterilized in Activated Glutaraldehyde 2.4\% (Cidex) for 10 minutes.

a) Exhaled NO level:

FeNO was measured on the first day of admission in recent-diagnosed cases or once pulmonary TB was diagnosed, according to the guidelines of American Thoracic Society and European Respiratory Society (ATS/ERS) [12], utilizing a hand-held portable device NO breath device, manufactured by Bedfont scientific ltd-England, 2011 (NO breath, Bedfont, UK). Patients were seated to perform the test, in the upright position with a nose clip off. Then to inspire as deeply as possible for three seconds then were asked to expire through device mouthpiece, maintaining ball in flow indicator in middle of a black band in the center of the tube, this was done aiming for keeping the rate of the expired air at a constant flow of $50 \mathrm{ml} / \mathrm{s}$ [13] [14].

To ensure a breath sample was right at the correct flow rate, the monitor was held upright all the time during the test. Repeated measurements were done after 10 minutes until two acceptable comparable values ( \pm 2.5 part per billion (ppb) for measurements $<35 \mathrm{ppb}$ and $\pm 5 \%$ for measurements $\geq 35 \mathrm{ppb}$ ) were performed (maximum 3 attempts) [11].

The mean of two adequate values for every patient was documented for analysis. Interpretation of FeNO levels was done according to ATS 2011 guidelines as follows [15]:

- FeNO $<20$ ppb: low (normal);

- FeNO 20 - 35 ppb: intermediate;

- FeNO > 35 ppb: high.

\section{b) Exhaled CO measurement: $\mathrm{CO}$ detector check plus}

All patients were acquiesced to the measurement of exhaled carbon monoxide by Co detector check plus, Tracy Rowland-Dorset Public Health, England. By MD Diagnostics Ltd. 15 Hollingworth Court, Turkey Mill, Ashford Road, Maid- 
stone, Kent ME14 5PP). Cases were advised to breathe into a cardboard tube attached to a handheld monitor. The monitor then displayed the results on its screen. They were requested to hold their breath for 15 seconds then breathe out slowly into the mouthpiece aiming to empty their lungs. The results were verified in parts per million (ppm) of carbon monoxide in breath.

Values were detected according British lung foundation 2017 for exhaled level [16]:

\begin{tabular}{cl}
\hline Reading & \multicolumn{1}{c}{ Suggests } \\
\hline$\cdot \geq 10 \mathrm{ppm}$ & - Recent exposure to a high level of carbon monoxide \\
$\cdot 5-9 \mathrm{ppm}$ & - Recent exposure to a moderate level of carbon monoxide \\
$\bullet 1-4 \mathrm{ppm}$ & - Recent exposure to a low level of carbon monoxide. \\
\hline
\end{tabular}

4) Radiological investigation in the form of Chest $\mathrm{X}$ ray (PA, lateral view) Chest radiograph scoring [17]:

A five-point CXR scoring tool to record the severity of lung abnormalities.

\begin{tabular}{cl}
\hline Grade I & Normal chest x-ray \\
\hline Grade II & Patchy atelectasis and/or pulmonary hyperinflation and/or bronchial thickenings \\
Grade III & Focal pulmonary consolidation affecting from one segment to one lobe \\
Grade IV & Multifocal consolidation \\
Grade V & Diffuse alveolar consolidation
\end{tabular}

\section{Statistical Analysis}

Data were analyzed with SPSS version 21. The normality of data was first tested with a one-sample Kolmogorov-Smirnov test. Qualitative data were described using number and percent. Association between categorical variables was tested using Chi-square test. ANOVA test was done between studied groups for all above mentioned statistical tests done, the threshold of significance is fixed at $5 \%$ level ( $p$-value).

\section{Results}

Table 1 demonstrated the demographic findings in studied cases. The total mean age was the higher than mean age in all groups. Mean age was higher in the latent group (group 2) followed by group 1 ( $32 \pm 11.23$ and $29 \pm 9.25$ years), unlike group 3 which presented $26 \pm 8.65$ years. Females were less affected than males in all studied groups and in total patients however group 3 was approximate. There were statistically significant differences between all the studied groups regarding sex. Pulmonary function parameters including FEV1, FVC, FEV1/FVC ratio and PEFR showed higher levels in latent TB group than PTB group but less than their peers in the control group with statistical significant difference regarding FVC and FEV1/FVC ratio (0.002, 0.036 respectively). 
Table 1. Demographic and pulmonary functions data of the studied groups.

\begin{tabular}{cccccc}
\hline & Total & Group 1 & Group 2 & Group 3 & p-value \\
& & $(\mathrm{PTB})(\mathrm{n}=48)(\mathrm{LTB})(\mathrm{n}=42)$ & $(\mathrm{CT})(\mathrm{n}=40)$ & \\
\hline Age (years) & $35 \pm 12.5$ & $29 \pm 9.25$ & $32 \pm 11.23$ & $26 \pm 8.65$ & 0.865 \\
\hline Gender Male Female & & & & & \\
& $94(72.3 \%)$ & $42(87.5 \%)$ & $31(73.8 \%)$ & $21(52.5 \%)$ & 0.0254 \\
& $36(27.7 \%)$ & $6(12.5 \%)$ & $11(26.2 \%)$ & $19(47.5 \%)$ & \\
\hline $\begin{array}{c}\text { Duration of illness } \\
\text { Median (Min-Max) }\end{array}$ & $9(4-15)$ & $10(3-25)$ & $11(6-20)$ & - & 0.906 \\
\hline $\begin{array}{c}\text { Pulmonary function } \\
\text { parameters }\end{array}$ & & & & & \\
FEV1 (L) & $2.36 \pm 0.54$ & $1.99 \pm 0.82$ & $2.34 \pm 0.74$ & $2.76 \pm 0.42$ & 0.219 \\
FVC (L) & $2.87 \pm 0.75$ & $2.76 \pm 1.06$ & $2.90 \pm 0.95$ & $3.30 \pm 0.52$ & 0.002 \\
FEV1/FCV ratio (\%) & $79.72 \pm 8.64$ & $74.21 \pm 17.29$ & $81.57 \pm 9.64$ & $83.63 \pm 4.75$ & 0.036 \\
PEFR (L/min) & 265.62 & $212 \pm 51.81$ & $256 \pm 38.07$ & $329 \pm 74.21$ & 0.493 \\
\hline
\end{tabular}

PTB (pulmonary tuberculosis); LTB (latent tuberculosis); CT (control); FEV1: Forced expiratory volume in one second; FVC: Forced vital capacity; PEFR: peak expiratory flow rate.

The total leukocytic count was higher in the tuberculous group than the latent one with no significant statistical differences. On one hand CRP showed a higher median level in pulmonary TB group followed by a the control group then laslty latent TB group. On the second hand, ESR median level and sputum eosinophilia mean percentage were higher in pulmonary TB patients than the other two groups. Mean FECO and FENO levels prevailed in pulmonary TB patients followed by Latent TB patients and lastly healthy volunteers $(42 \pm 12.32 / 5 \pm 0.16$ \& $38 \pm 8.25 / 6 \pm 2.25$ and $23 \pm 3.25 / 2 \pm 0.40$ respectively). Statistical significant differences were documented between three groups concerning sputum eosinophilia, ESR, FECO and FENO. Radiological findings were prominent in PTB group [grade III was detected in more than $50 \%$ in PTB however grade VI accounted for $25 \%$, however, grade II and V were identified only in $12.5 \%$ and $8.33 \%$ ]. Radiological presentations were less evident in latent TB group [grade III was less than $5 \%$, as well as other grades were less than $3 \%$ ] and nearly absent in healthy group. Statistical significant differences were recognized between the three groups concerning group II, III, IV patterns (Table 2).

\section{Discussion}

Pulmonary tuberculosis has been boomed for many years as most ancient disease and inveterate infection of humankind for its mass dramatic impact on body systems not only the lungs. Diagnosis of pulmonary tuberculosis has drawn attention for all specialties to attain the access of early diagnostic modalities in order to guard against debilitating sequels.

Inhaled inflammatory markers estimation shared to a greater extent as being evidence of respiratory disease occurrence and a trace of their prognosis. 
Table 2. Laboratory and radiological data of the studied groups.

\begin{tabular}{cccccc}
\hline & Total & $\begin{array}{c}\text { Group 1 (PTB) } \\
(\mathbf{n}=48)\end{array}$ & $\begin{array}{c}\text { Group 2 } \\
\text { (LTB) }(\mathrm{n}=42)\end{array}$ & $\begin{array}{c}\text { Group 3 (CT) } \\
(\mathrm{n}=40)\end{array}$ & p-value \\
\hline $\begin{array}{c}\text { TLC (1000/ml) } \\
\text { Mean +/-SD }\end{array}$ & $22.21 \pm 6.05$ & $21.65 \pm 4.63$ & $15.04 \pm 5.5$ & $10.2 \pm 3.06$ & 0.184 \\
$\begin{array}{c}\text { CRP (mg/l) Median } \\
\text { (minimum-maximum) }\end{array}$ & $56(12-132)$ & $62(24-132)$ & $46(24-132)$ & $52(24-96)$ & 0.089 \\
$\begin{array}{c}\text { ESR (mm/hr) Median } \\
\text { (minimum-maximum) }\end{array}$ & $75(18-112)$ & $84(28-128)$ & $65(12-85)$ & $25(9-63)$ & $0.023 *$ \\
Sputum Eosinophil (\%) & $12.11 \pm 2.86$ & $13.38 \pm 3.31$ & $12.38 \pm 2.38$ & $9.05 \pm 3.01$ & $<0.001 *$ \\
$\begin{array}{c}\text { FeNO (ppb) } \\
\text { Mean +/-SD }\end{array}$ & $33 \pm 10.2$ & $42 \pm 12.32$ & $38 \pm 8.25$ & $23 \pm 3.25$ & $0.0356 *$ \\
FeCO (ppm) & $5 \pm 0.16$ & $9 \pm 2.14$ & $6 \pm 2.25$ & $2 \pm 0.40$ & $0.0165 *$ \\
Mean +/-SD & & & & & \\
Radiological grades & & & & & \\
Grade I & $1(0.76 \%)$ & 0 & $1(2.38 \%)$ & 0 & 0.258 \\
Grade II & $8(6.15 \%)$ & $6(12.5 \%)$ & $1(2.38 \%)$ & $1(2.5 \%)$ & $0.0236 *$ \\
Grade III & $28(21.53 \%)$ & $26(54.16 \%)$ & $2(4.76 \%)$ & 0 & $0.0045 *$ \\
Grade IV & $13(10 \%)$ & $12(25 \%)$ & $1(2.38 \%)$ & 0 & $0.0032 *$ \\
Grade V & $4(3.07 \%)$ & $4(8.33 \%)$ & 0 & 0 & 0.925 \\
\hline
\end{tabular}

$\mathrm{PaO}$ /FiO2: ratio of arterial oxygen partial pressure to fractional inspired oxygen; FeNO: fractional exhaled nitric oxide; TLC: total leukocyte count; CRP: C-reactive protein.

Multivariate analysis carried out by Jose W. L Opez et al. [18] stated no significant association between diagnosis of TB and FeNO level after correction for age, gender, BMI, height and HIV status.

In our research mean age was insignificantly higher in the LTB group followed by the PTB group ( $32 \pm 11.23$ and $29 \pm 9.25$ years), unlike the control group that presented $26 \pm 8.65$ years. Females were insignificantly less affected than males in all studied groups and in total patients apart from the control group that were approximate. Depending on the duration of illness as an indicator for disease severity and in correlation with exhaled marker level could not be applied in this study due to difficulties that were encountered in machine calibration, limited number for the device to perform in addition to patient follow up problems.

In L Opez study, on one hand, the median FeNO levels were $13 \mathrm{ppb}$ in $\mathrm{TB}$ participants of and $15 \mathrm{ppb}$ in healthy non-diseased controls, without statistically significant differences. On the other hand median FeNO measured levels in positive tuberculin controls were $18 \mathrm{ppb}$, negative tuberculin controls $13 \mathrm{ppb}$, and TB patients $13 \mathrm{ppb}$ and were not significantly different between groups. However, in our work measurement of FeNo level in pulmonary TB patients showed higher levels (42 ppb) than latent TB patients (38 ppb) and lastly healthy volunteers that demonstrated lowest detected level $(23 \mathrm{ppb})$. This difference in FeNo 
level between pulmonary $\mathrm{TB}$ patients and latent $\mathrm{Tb}$ patients could be explained by the pathophysiological inflammatory mechanisms of pulmonary parenchyma owing to increased macrophages activity and lack of balance in iNO synthetase enzyme system. In our study patients with immune disorders or other chronic pulmonary disorders were excluded for fear of false-negative results.

Previous human studies on FeNO had shown contradictory results. The largest human experiment to date in Indonesia found lower mean FeNO levels in TB cases with no convincing explanation, although data coincided considerably with those in healthy controls, and similar data were observed in an Ethiopian study which included HIV-positive patient [19] [20]. A study in Taiwan had reported increased FeNO levels in active TB patients, assuming increased lung macrophage activity and up-regulation of iNOS [10]. They found a median FeNO value of $15 \mathrm{ppb}$ in healthy control subjects, parallel to values reported in Vietnamese construction workers (15 ppb) and healthy controls in the Indonesian study (16.6 ppb), but higher than that in controls in the Taiwanese study (6.5 \pm 0.9 $\mathrm{ppb})$ and lower than mean values observed in Korean controls $(27.06 \pm 10.8$ ppb) and Yhi study 2016 [21] [22]. The FeNO level unevenness in healthy controls was furthermore demonstrated in the Vietnam study: although FeNO was greater in TB participants compared with a subgroup of healthy hospital workers, they were not significantly different on comparison with healthy construction workers [23].

The fractional concentration of exhaled nitric oxide that had been used as a measure of type 2 airway inflammation showed correlations with a sputum eosinophilia and Th2 cytokines including IL-5 and IL-13 [24] [25]. As a Th1 response predominates in $\mathrm{TB}$, this might clarify why they found no difference in FeNO levels between TB patients and controls [26].

In our work in Mansoura chest hospital sputum eosinophilia was identified in pulmonary TB and latent TB patients that might be related to one variant in this type of infection. ESR and sputum eosinophilia presented higher levels in pulmonary TB patients than the other two groups.

Elevated exhaled NO and NOS2 expression in alveolar macrophages is found in patients with active tuberculosis and is decreased with anti-tuberculous therapy [10]. A longitudinal study in Korean TB participants also demonstrated no significant change following 8 weeks of treatment [21]. Likewise, only a very small variation was observed in mean FeNO levels at treatment completion in the Indonesian study, $10.7-15.1 \mathrm{ppb}$, which falls within the precision range for the portable NO analyzer device used ( $\pm 5 \mathrm{ppb}$ for values $<50 \mathrm{ppb}$ ).

Carbon monoxide ( $\mathrm{CO}$ ) was recognized as a gas that may be generated endogenously and was detectable in exhaled air. There were three major sources of $\mathrm{CO}$ in exhaled air: exogenous $\mathrm{CO}$, enzymatic degradation of heme, non-heme-related release initiated by (lipid peroxidation, bacteria, hypoxia, tumor necrosis factor, reactive nitrogen and oxygen intermediates [27] [28] and also by MTB infection [29] [30]. CO gas resulted from the degradation of hemoglobin by the enzyme heme oxygenase $(\mathrm{HO})$ that was mostly exhaled, and approximately $15 \%$ had ari- 
sen from the degradation of myoglobin, NO synthases, catalase, guanylyl cyclase and cytochromes [31]. Several bacteria yielded CO, and less than $1 \%$ is unbound and dissolved in body fluid [32]. Furthermore, in response to PTB infection, host cells produced a variety of toxic compounds to mediate microbial eradication nitric oxide (NO), and carbon monoxide (CO) are some of them. Formerly, multiple studies [28] [29] found that throughout MTB infection, HO-1 enzyme was induced in macrophages in infection suggesting that increased levels of $\mathrm{CO}$ might be observed during MTB infection. In our work exhaled CO was statistically higher in PTB group being more than four folds increase in the measured level than normal healthy volunteers and 50\% increase than latent tuberculous patients.

Radiological findings were prominent in PTB group, grade III more than 50\% was detected in PTB however grade VI accounted for $25 \%$. Grade II and V were identified in lower percentages.

Radiological presentations were evident in latent TB group as $(2.38 \%)$ in grade I and II and minimal in healthy group. These findings were related to previous pulmonary infections other than TB. These findings were reasonable with most diseased patients and these imaging tools were held in the study to correlate with clinical progression of the disease and to be supporting aids in the diagnosis. Many limitations had been encountered in our study the first one represented in application of serial monitoring that had been canceled due to apparatus calibration as mentioned earlier, the second was in comparison between pulmonary and extrapulmonary patients was it differ, that needed larger multi-organ studies. The third was in the strong need for recent well-documented sterilization techniques for portable spirometer and gas analyzer to hinder the transmission of infection in subsequent studies to save cost of sensors used in the three groups.

\section{Conclusion}

Measurement of exhaled NO and CO level in expired air can entitle a simple non-invasive approach in the pathway of diagnosis of pulmonary tuberculosis in both active and latent phases and differentiate them from healthy non-affected cases.

\section{Conflicts of Interest}

The authors declare no conflicts of interest regarding the publication of this paper.

\section{References}

[1] Parsons, L.M., et al. (2011) Laboratory Diagnosis of Tuberculosis in Resource-Poor Countries: Challenges and Opportunities. Clinical Microbiology Reviews, 24, 314-350. https://doi.org/10.1128/CMR.00059-10

[2] Lawn, S.D. (2012) Point-of-Care Detection of Lipoarabinomannan (LAM) in Urine for Diagnosis of HIV-Associated Tuberculosis: A State of the Art Review. BMC Infectious Diseases, 12, Article No. 103. https://doi.org/10.1186/1471-2334-12-103 
[3] Boots, A.W., Van Berkel, J.J.B.N., Dallinga, J.W., Smolinska, A., Wouters, E.F. and Van Schooten, F.J. (2012) The Versatile Use of Exhaled Volatile Organic Compounds in Human Health and Disease. Journal of Breath Research, 6, Article ID: 027108. https://doi.org/10.1088/1752-7155/6/2/027108

[4] Kolk, A.H.J., et al. (2012) Breath Analysis as a Potential Diagnostic Tool for Tuberculosis. The International Journal of Tuberculosis and Lung Disease, 16, 777-782. https://doi.org/10.5588/ijtld.11.0576

[5] Dang, N.A., Janssen, H.G. and Kolk, A.H.J. (2013) Rapid Diagnosis of TB Using GC-MS and Chemometrics. Bioanalysis, 5, 3079-3097. https://doi.org/10.4155/bio.13.288

[6] Beccaria, M., et al. (2018) Preliminary Investigation of Human Exhaled Breath for Tuberculosis Diagnosis by Multidimensional Gas Chromatography-Time of Flight Mass Spectrometry and Machine Learning. Journal of Chromatography B, 1074-1075, 46-50. https://doi.org/10.1016/j.jchromb.2018.01.004

[7] Horváth, I., et al. (2017) A European Respiratory Society Technical Standard: Exhaled Biomarkers in Lung Disease. European Respiratory Journal, 49, Article ID: 1600965. https://doi.org/10.1183/13993003.00965-2016

[8] Das, M.K., et al. (2014) Investigation of Gender-Specific Exhaled Breath Volatome in Humans by GCxGC-TOF-MS. Analytical Chemistry, 86, 1229-1237. https://doi.org/10.1021/ac403541a

[9] Blanchet, L., et al. (2017) Factors That Influence the Volatile Organic Compound Content in Human Breath. Journal of Breath Research, 11, Article ID: 016013. https://doi.org/10.1088/1752-7163/aa5cc5

[10] Wang, C.-H., et al. (1998) Increased Exhaled Nitric Oxide in Active Pulmonary Tuberculosis Due to Inducible NO Synthase Up-Regulation in Alveolar Macrophages. European Respiratory Journal, 11, 809-815. https://doi.org/10.1183/09031936.98.11040809

[11] Biernacki, W. (1998) Carbon Monoxide in Exhaled Air in Patients with Lower Respiratory Tract Infection. European Respiratory Journal, 12, 345S.

[12] A. T. Society (2005) European Respiratory Society. ATS/ERS Recommendations for Standardized Procedures for the Online and Offline Measurement of Exhaled Lower Respiratory Nitric Oxide and Nasal Nitric Oxide, 2005. The American Journal of Respiratory and Critical Care Medicine, 171, 912-930. https://doi.org/10.1164/rccm.200406-710ST

[13] Pisi, R., Aiello, M., Tzani, P., Marangio, E., Olivieri, D. and Chetta, A. (2010) Measurement of Fractional Exhaled Nitric Oxide by a New Portable Device: Comparison with the Standard Technique. Journal of Asthma, 47, 805-809. https://doi.org/10.3109/02770903.2010.485667

[14] Harnan, S.E., et al. (2015) Measurement of Exhaled Nitric Oxide Concentration in Asthma: A Systematic Review and Economic Evaluation of NIOX MINO, NIOX VERO and Nobreath. Health Technology Assessment, 19, 1-330. https://doi.org/10.3310/hta19820

[15] Dweik, R.A., et al. (2011) An Official ATS Clinical Practice Guideline: Interpretation of Exhaled Nitric Oxide Levels (FENO) for Clinical Applications. American Journal of Respiratory and Critical Care Medicine, 184, 602-615. https://doi.org/10.1164/rccm.9120-11ST

[16] Lawin, H., et al. (2017) Exhaled Carbon Monoxide: A Non-Invasive Biomarker of Short-Term Exposure to Outdoor Air Pollution. BMC Public Health, 17, Article No. 320. https://doi.org/10.1186/s12889-017-4243-6 
[17] Taylor, E., et al. (2015) A Chest Radiograph Scoring System in Patients with Severe Acute Respiratory Infection: A Validation Study. BMC Medical Imaging, 15, Article No. 61. https://doi.org/10.1186/s12880-015-0103-y

[18] López, J.W., et al. (2018) Exhaled Nitric Oxide Is Not a Biomarker for Pulmonary Tuberculosis. The American Journal of Tropical Medicine and Hygiene, 98, 1637-1639. https://doi.org/10.4269/ajtmh.17-0425

[19] Ralph, A.P., et al. (2013) Impaired Pulmonary Nitric Oxide Bioavailability in Pulmonary Tuberculosis: Association with Disease Severity and Delayed Mycobacterial Clearance with Treatment. The Journal of Infectious Diseases, 208, 616-626. https://doi.org/10.1093/infdis/jit248

[20] Idh, J., et al. (2008) Nitric Oxide Production in the Exhaled Air of Patients with Pulmonary Tuberculosis in Relation to HIV Co-Infection. BMC Infectious Diseases, 8, Article No. 146. https://doi.org/10.1186/1471-2334-8-146

[21] Yhi, J.Y., et al. (2016) Measurement of Levels of Fractional Exhaled Nitric Oxide in Patients with Pulmonary Tuberculosis. The International Journal of Tuberculosis and Lung Disease, 20, 1174-1180. https://doi.org/10.5588/ijtld.15.1019

[22] Van Beek, S.C., Nhung, N.V., Sy, D.N., Sterk, P.J., Tiemersma, E.W. and Cobelens, F.G.J. (2011) Measurement of Exhaled Nitric Oxide as a Potential Screening Tool for Pulmonary Tuberculosis.

[23] Olin, A.C., Bake, B. and Torén, K. (2007) Fraction of Exhaled Nitric Oxide at 50 $\mathrm{ml} / \mathrm{s}$ : Reference Values for Adult Lifelong Never-Smokers. Chest, 131, 1852-1856. https://doi.org/10.1378/chest.06-2928

[24] Kim, M.-A., Shin, Y.S., Pham, L.D. and Park, H.-S. (2014) Adult Asthma Biomarkers. Current Opinion in Allergy and Clinical Immunology, 14, 49-54. https://doi.org/10.1097/ACI.0000000000000028

[25] Barnes, P.J. (2008) The Cytokine Network in Asthma and Chronic Obstructive Pulmonary Disease. Journal of Clinical Investigation, 118, 3546-3556. https://doi.org/10.1172/JCI36130

[26] O’Garra, A., Redford, P.S., McNab, F.W., Bloom, C.I., Wilkinson, R.J. and Berry, P.R. (2013) The Immune Response in Tuberculosis. Annual Review of Immunology, 31, 475-527. https://doi.org/10.1146/annurev-immunol-032712-095939

[27] Slebos, D.J., Ryter, S.W. and Choi, A.M.K. (2003) Heme Oxygenase-1 and Carbon Monoxide in Pulmonary Medicine. Respiratory Research, 4, 7. https://doi.org/10.1186/1465-9921-4-7

[28] Donnelly, L.E. and Barnes, P.J. (2001) Expression of Heme Oxygenase in Human Airway Epithelial Cells. American Journal of Respiratory Cell and Molecular Biology, 24, 295-303. https://doi.org/10.1165/ajrcmb.24.3.4001

[29] Shiloh, M.U., Manzanillo, P. and Cox, J.S. (2008) Mycobacterium Tuberculosis Senses Host-Derived Carbon Monoxide during Macrophage Infection. Cell Host Microbe, 3, 323-330. https://doi.org/10.1016/j.chom.2008.03.007

[30] Kumar, A., et al. (2008) Heme Oxygenase-1-Derived Carbon Monoxide Induces the Mycobacterium Tuberculosis Dormancy Regulon. The Journal of Biological Chemistry, 283, 18032-18039. https://doi.org/10.1074/jbc.M802274200

[31] Berk, P.D., Rodkey, F.L., Blaschke, T.F., Collison, H.A. and Waggoner, J.G. (1974) Comparison of Plasma Bilirubin Turnover and Carbon Monoxide Production in Man. Journal of Laboratory and Clinical Medicine, 83, 29-37.

[32] Levine, A.S., Bond, J.H., Prentiss, R.A. and Levitt, M.D. (1982) Metabolism of Carbon Monoxide by the Colonic Flora of Humans. Gastroenterology, 83, 633-637. https://doi.org/10.1016/S0016-5085(82)80200-X 